\title{
The Implications of Teachers' Professional Attributes on Assimilating a Computerized Learning and Management System in an Israeli School: A Case Study
}

\author{
Orit Avidov-Ungar ${ }^{1}$, Noga Magen-Nagar ${ }^{2}$ \\ ${ }^{1}$ The Open University, Achva Academic College \\ ${ }^{2}$ Ministry of Education, Gordon College \\ Email: oritav@openu.ac.il,nogamar@biu.013.net.il
}

Received 2012

\begin{abstract}
Assimilating processes of change in teaching methods and their application in school entail considerable difficulty. The teachers' ability and skills as a professional-pedagogic entity in the process of change is the first factor for the occurrence of radical change. This study examines the extent to which teachers' professional attributes predict resistance to change when assimilating a computerized learning management and teaching system (LMS) in school. Teachers from an experimental high school in Israel, which is participating in a comprehensive reform to integrate a computerized LMS system into schools in Israel, participated in this study. A questionnaire regarding resistance to change was distributed to 60 teachers and analyzed using path analysis in structural equation modeling with the statistical AMOS 7.0 (Analysis of Moment Structures) software (Arbuckle, 2006). The findings indicate that a high level of computer literacy amongst teachers predicts low resistance to change; school seniority predicts high resistance to change, as does a key role in school. The contribution of the study lies in understanding that, till now, these attributes were considered to be background attributes. The study identifies their unique impact on the teachers' readiness to assimilate change in school.
\end{abstract}

Keywords:

\section{Introduction}

This study aims to examine the assimilation of a computerized system for managing learning and teaching (LMS) from the professional perspective of the school teacher. The computerized system explored in this study is the LMS software that was developed in Israel, and is in use in schools worldwide (Macfadyen \& Dawson, 2010). This system is based on the approach that teachers are all principals in their subject, and therefore need organized information that will help them from the administrative and pedagogic perspectives (Blau \& Hameiri, 2012). Research finds that assimilating processes of change in teaching methods and their application in school entail considerable difficulty. The teachers' ability and skills as a professional-pedagogic factor in the process of change is the prime cause of radical change in innovative pedagogic perception in the education system (Fullan \& Smith, 1999; De Freitas \& Oliver, 2005; Cunningham, 2009; Halverson \& Smith, 2010; Selwyn, 2010). Apart from the teachers' professional abilities, the conditions and organizational culture were also found to affect their approach to the change (Coppieters, 2005), and accordingly, to impact the effectiveness of the assimilation of innovative technologies (Zimmerman, 2006; Avidov-Ungar, 2010).

This study assumes that the teacher is an important and key figure, whose professional attributes are therefore a significant factor in the processes of change in school (Collinson, Kozina, Lin, Yu-Hao Ling, Matheson, Newcombe \& Zogla, 2009). The teachers' professionalism in assimilating the innovative technology is described in this study from several professional perspectives, such as teaching seniority, school seniority, and role in school. Studies find that the resistance which is hardest to handle stems from the teachers' perception that the change harms their strength and status as professionals (Buchanan \& Boddy, 1992; Chong, 2008). In other words, the greater the teachers' professional and school seniority the stronger will be their resistance to change. The more a teacher fills a dominant role in school, the more involved and committed the teacher will be, and thus will contribute to the change that the school adopts (Baskin, 2004). The additional variable, computer literacy, is included in the research as an important and influential component in assimilating the technological LMS (Woodrow, 1992; Virkus 2003; Koschmann, 2005; Harris \& Hofer, 2009). The study focuses on a high school in Israel, one of the pioneering schools leading change in assimilating a computerized LMS as part of a national reform.

\section{The Research Objective}

The study aims to explore the degree to which the teachers' professional attributes predict resistance to change in assimilating a computerized LMS in school, from the cognitive, emotional and behavioral aspects.

\section{The Research Hypotheses}

Professional attributes contribute to the explanation of the 
variance in the level of resistance to change relative to assimilating the computerized LMS, from the cognitive, emotional and behavioral aspects, as follows:

a) The greater the teaching and school seniority the greater will be the resistance to assimilating the computerized system.

b) The more central the role in school, the less will be the resistance to change regarding assimilating the computerized system.

c) The greater the teacher's computer literacy the less will be the resistance to change regarding assimilating the computerized system.

\section{The Research Participants}

Sixty out of 96 teachers (62/5\%) in the experimental high school participated in the study, 40 of whom were female (66.7\%) and 20 male (33.3\%). Most of the teachers (60\%) had considerable teaching seniority and had been teaching for more than ten years; $40 \%$ of the teachers had worked there for one to five years and another $35 \%$ had worked in school for more than five years. Those working in the school for one year account for $12 \%$.

\section{The Research Tools}

The degree of resistance to assimilating a computerized system was measured using a questionnaire developed by Goldrat (2001). It included 16 statements that refer to three components of resistance to change - cognitive, emotional and behavioral. Cronbach's alpha for the reliability of the questionnaire was 0.92 .

\section{The Research Findings}

A path analysis was conducted using structural equation modeling to explore the impact of the teachers' professional attributes on their attitudes towards assimilating a computerized LMS in school, using the AMOS 7.0 (Analysis of Moment Structures) statistical software (Arkbuckle, 2006).

In this path analysis, independent (exogenous) variables were defined that were the professional attributes, and included the teacher's role in school and teaching seniority. This was followed by the mediating (endogenous) variables which were the teacher's seniority at school, and the level of mastery of computer literacy (CL). The additional endogenous variables were the three indices of resistance to the use of the computerized system. At the first stage of the analysis, the measurement model was evaluated using the four indices $-\chi^{2}$, RMSEA, NFI and CFI - that are used to examine the model most suited to reality (Bentler \& Bonett, 1980).

The results of the measurement model show that the value of $0.77(\mathrm{df}=2) \chi^{2}$ is not statistically significant $(\mathrm{p}=.681)$. The RMSEA index (.000) is lower than .05; the NFI index (.992) is very high and approaches 1 ; and CFI (1.000). These measurements provide the most fundamental indication of how well the proposed theory fits the data. The second phase evaluated the structural model that categorizes the relationships and effects among the variables as shown in Figure 1.

Examination of Figure 1 shows that teaching seniority explains the variance in the teacher's seniority in school (24\%). Teaching seniority, school seniority and CL together explain the variance in the cognitive and the behavioral resistance towards the use of the computerized system (29\% and 20\% respectively). The school's role and CL together explain the variance in emotional resistance towards the use of the computerized system (28\%). Hence one may claim that the factors included in the model explain well the teachers' resistance regarding the cognitive, the emotional, and the behavioral facets relative to the use of the computerized system.

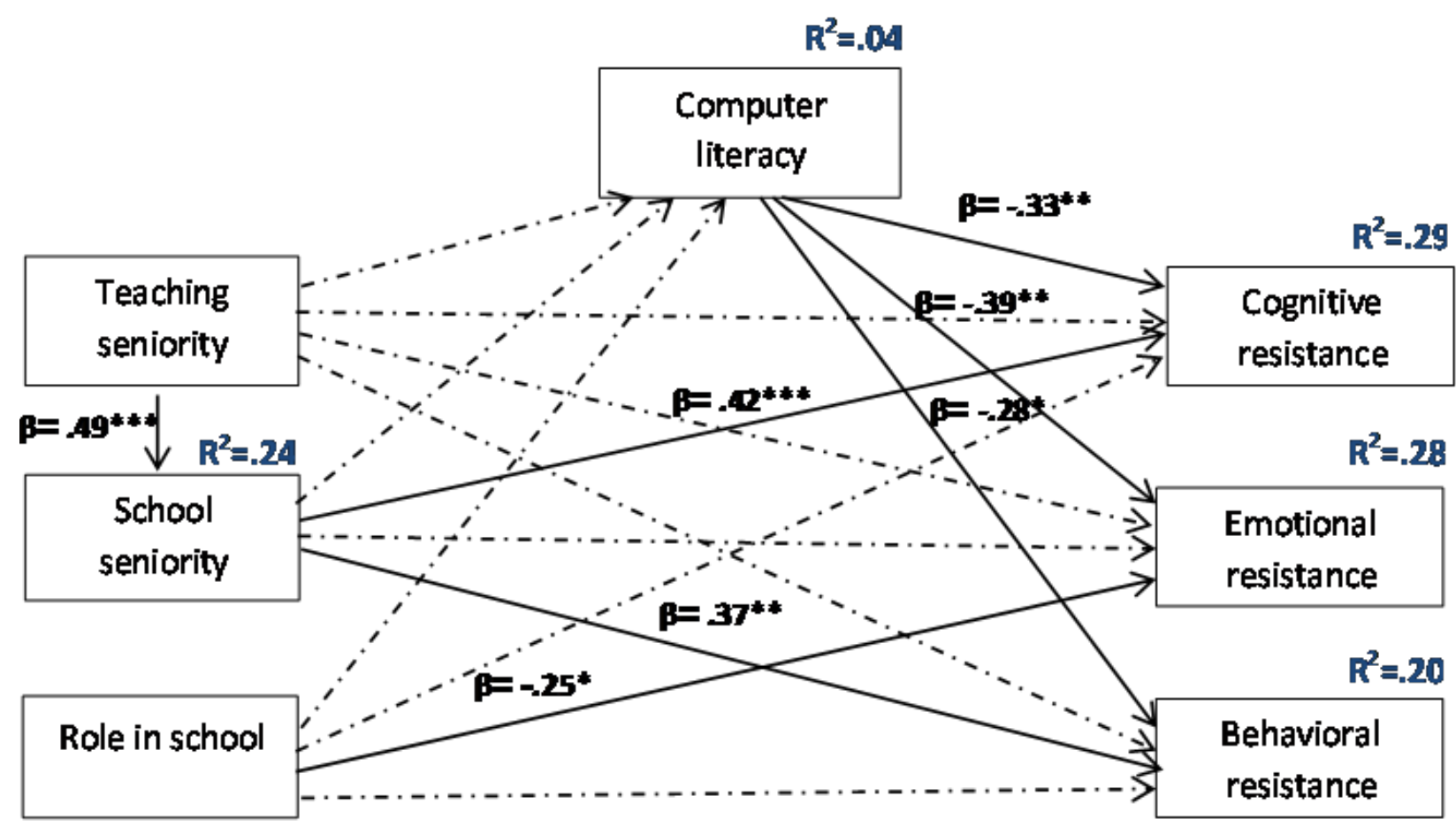

Figure 1.

The results of the path analysis for predicting opposition to the use of the computerized system. 
The path coefficients were examined according to the direct impact and thereafter according to the indirect impact. The chart shows that the "teaching seniority" variable does not affect the variables of "level of CL", "cognitive resistance", "emotional resistance", and "behavioral resistance". The variable "school seniority" has a distinct positive, strong impact on cognitive resistance to using the computerized system ( $\beta$ $=.42^{* * *}$ ), and on behavioral resistance to using the computerized system $\left(\beta=.37^{* *}\right)$, but not significantly on emotional resistance and on the level of CL. In other words, the more years the teachers accumulate in school, the greater their resistance to using the computerized system from the cognitive and the behavioral aspects. The "school role" variable has a distinct, negative impact of moderate strength on the emotional resistance to using the computerized system $\left(\left(\beta=-.25^{*}\right)\right.$ but is not distinct regarding cognitive resistance, behavioral resistance and the level of CL. In other words, the more teachers fulfill key roles in school, (as year grade coordinator or subject coordinator) the greater their emotional resistance to using the computerized system. The "CL" variable has a distinct negative, moderate to strong impact on cognitive resistance to using the computerized system $\left(\beta=-.33^{* *}\right)$, on emotional resistance to using the LMS $(\beta=-.39 * *)$, and on behavioral resistance to using the computerized system $\left(\beta=-.28^{*}\right)$. In other words, the greater the teachers' CL, the less their resistance to using the computerized system from the cognitive, the emotional, and the behavioral aspects.

Examination of the indirect impact finds that "teaching seniority" distinctly, strongly and positively affects "school seniority" ( $\left.\beta=.49^{* * *}\right)$ and cognitive and behavioral resistance $\beta=.42 * * *$ and $\beta=-.37 * *$ respectively. However, there is no indirect impact on the variables "teaching seniority", "school seniority", and "role in school" on the three components of resistance when the mediating variable is the level of CL.

\section{Discussion and Conclusions}

The research findings support the hypotheses. The findings of the SEM path analysis are innovative, and even expand the significance of the professional attributes of teaching seniority, school seniority, role in school, and level of CL relative to the assimilation of technological change. Until now, these attributes were considered to be the teachers' background and personal attributes, each with its unique impact on their readiness to accept change in general (Fullan \& Smith, 1999; De Freitas \& Oliver, 2005; Cunningham, 2009; Halverson \& Smith, 2010; Selwyn, 2010) and technological change in general (De Freitas \& Oliver, 2005). In the current study these attributes were analyzed simultaneously along a sequence and found influences of varying intensity for predicting resistance to change. The high level of the teacher's CL predicts low resistance to change, particularly in the personal assimilation of LMS in school. This finding complements other studies that find that the teachers' technological knowledge is very important relative to their attitudes towards technological change with LMS in school (Ogobonna \& Harris 2003; Carter, 2008; Coffman, 2009). Similarly, and as in other studies, greater school seniority was found to predict high resistance to change (Hart, 1987).

The current study finds that a key role in school predicts high resistance, in contrast to the findings of other studies (Baskin, 2004). The reason for this may stem from the perception of the essence of the school role, that does not testify necessarily to involvement and participation in decision-making and processes of change, but to coordinating a subject from the administrative, limited and narrow perspective (Avidov-Ungar \& Friedman, 2011).

The research findings further indicate that school seniority, role in school, and CL predict resistance to change directly, in contrast to teaching seniority that indirectly predicts resistance to change. These findings indicate the differences between types of professional attributes amongst teachers, thus teaching seniority is a demographic-personal attribute, similar to gender and education, while school seniority, role in school and CL are attributes that the teacher "acquires" in school, where he teaches, and they are inherently connected to the organizational culture (Borko, 2004). Therefore, attributes of this type may directly affect resistance to processes of change in school, as they may also affect resistance to assimilating a computerized system for teaching and learning. One may therefore also assume that resistance to change will be manifested in all the components of the attitude - cognitive, emotional and behavioral - and they are likely to contribute to better understanding of the future behavior of the teacher relative to the assimilation of the computerized LMS. Furthermore, the research conclusions testify to the fact that CL, school seniority and role in school are professional attributes that reflect the organizational culture, and their implications for the level of resistance to change are direct and significant. Accordingly, improvement in school culture, manifested mainly in nurturing the teachers' professional attributes, should be seen as a central element in reducing resistance to change when assimilating the LMS in school.

\section{REFERENCES}

Arbuckle, J. L. (2006). AMOS 7. 0 user's guide. Chicago: SPSS. Avidov-Ungar, O., \& Friedman, Y. (2011). Empowering teachers essence and models. Information available to the professional. Jerusalem: Henrietta Szold Institute (Hebrew).

Avidov-Ungar, O. (2010). "Islands of Innovation" or "Comprehensive Innovation" Assimilating educational technology in teaching, learning, and management: A case study of school networks in Israel. Interdisciplinary Journal of E-Learning and Learning Objects, 6, 259-280.

Baskin, E. F. (2004). Change management concepts and models: Sponsorship, early adopters, and the development of urban teachers. In R.B. Cooter, Jr. (Ed.), Perspectives on rescuing urban literacy education: Spies, saboteurs, and saints (pp. 25-40). Mahwah, NJ: Erlbaum.

Bentler, P. M., \& Bonett, D. G. (1980). Significance tests and goodness of fit in the analysis of covariance structures. Psychological Bulletin, 88, 588-606.

Blau, I. \& Hameiri, M. (2012). Teacher-families online interactions and gender differences in parental involvement through school data system: Do mothers want to know more than fathers about their children? Computers \& Education, 59, 701-709.

Borko, H. (2004). Professional development and teacher learning: Mapping the terrain. Educational Researcher Journal, 33 (8), 3-15.

Buchman, D., \& Boddy, D. (1992). The expertise of the change agent. Hemel Hempstead: Prentice Hall.

Carter, E. (2008). Successful change requires more than change management. The Journal for Quality \& Participation, 31 (1), 20-23.

Chong, K. H. (2008). Coping with conflict, confronting resistance: Fieldwork emotions and identity management in a South Korean evangelical community. Qualitative Sociology, 31(4), 36-390.

Coffman, T. (2009). Getting to the heart of technology integration: Virginia's instructional technology re-source teacher program. Learning and Learning with Technology, 36 (7), 20-23. 


\section{O. AVIDOV-UNGAR, N. MAGEN-NAGAR}

Collinson, V., Kozina, E., Lin, Yu-Hao K., Ling, L., Matheson, I., Newcombe, L., \& Zogla, I. (2009). Professional development for teachers: A world of change. European Journal of Teacher Education, 32 (1), 3-19.

Coppieters, P. (2005). Turning schools into learning organizations. European Journal of Teacher Education, 28 (2), 129-139.

Cunningham, C. A. (2009). Transforming schooling through technology: Twenty-first-century approaches to participatory learning. Education and Culture, 25 (2), 46-61.

Goldrat, A. (2001). The connection between the perception of uncertainty, tolerance for ambiguity and a sense of pressure and the attitude of employees towards organizational change. Jerusalem: Henrietta Szold Institute (Hebrew).

De Freitas, S., \& Oliver, M. (2005). Does e-learning policy drive change in higher education? A case study relating models of organizational change to e-learning implementation. Journal of Higher Education Policy and Management, 27 (1), 81-95.

Fullan, M., \& Smith, G. (1999). Technology and the problem of change. Available at: http://www.michaelfullan.ca/Articles_98-99/12_99.pdf

Halverson, R., \& Smith, A. (2009). How new technologies have (and have not) changed teaching and learning in schools. Journal of Computing in Teacher Education, 26 (2), 49-55.

Hart, A. W. (1987). A career ladder's effect on teacher career and work attitudes. American Educational Research Journal,

$24(4)$ 479-503.

Koschmann, T. (2005). Medical education and computer literacy: learning about, through, and with computers. Acad Med. 70, 818-821.

Macfadyen, L. P., \& Dawson, S. (2010). Mining LMS data to develop an "early warning system" for educators: A proof of concept. Computers \& Education, 54, 588-599.

Ogobonna, E., \& Harris L. C. (2003). Innovation organizational structure and performance. Journal of Organizational Change Management, 16 (5), 512-533.

Selwyn, N. (2010). Looking beyond learning: Notes towards the critical study of educational technology. Journal of Computer Assisted Learning, 26 (1), 65-73.

Virkus S. (2003). Information literacy in Europe: a literature review. Information Research, 8 (4), 1-159. http://informationr.net/ir/8-4/paper159.html

Woodrow, J. E. J. (1992). The influence of programming training on the computer literacy and attitudes of pre-service teacher. Journal of Research on Computing in Education, 25 (2), 200-219.

Zimmerman, J. (2006). Why some teachers resist change and what principals can do about it. NASSP Bulletin, 90 (3), 238-249. 